Tohoku J. Exp. Med., 2003, 199, 85-93

\title{
Colorectal Cancer in Young Patients: Characteristics and Outcome
}

\author{
Süleyman Alici, N. Faruk Aykan, Burak Sakar, Gulistan Bulutlar, Esra \\ Kaytan and ERKan Topuz \\ Institute of Oncology, University of Istanbul, Istanbul, Turkey
}

Alici, S., Aykan, N.F., Sakar, B., Bulutlar, G., Kaytan, E. and Topuz, E. Colorectal Cancer in Young Patients: Characteristics and Outcome. Tohoku J. Exp. Med., 2003, 199 (2), 85-93—Colorectal cancer is predominantly a disease of the elderly population, but this disease is unusual in patients 40 years of age or under, and controversy persists as to prognosis in this subset of patients. The aim of this study was to determine the clinicopathologic features and their impact on patients survival of colorectal cancer in patients aged 40 years or younger, and to compare them with those of older patients. The records of 466 patients with non-metastatic colorectal adenocarcinoma who were referred between 1991 and 1999 to the University of Istanbul, Institute of Oncology, following curative surgery were retrospectively analysed. The clinicopathologic features of $84(18 \%)$ colorectal cancers (group A; male : female ratio $48: 36$ ) which occurred in patients aged 40 years or younger were compared with 382 colorectal cancers in older patients (group B; male: female ratio $194: 188$ ). Patient gender, performance status, $\mathrm{T}$ stage, $\mathrm{N}$ stage, TNM stage, histologic grade, location of tumor, lymphatic invasion, serum levels of LDH and CEA, and survival rates were compared as prognostic factors. There was no statistically significant difference between group A and group B with respect to patient gender, performance status, T stage, $\mathrm{N}$ stage, TNM stage, histologic grade, location of tumor, serum levels of $\mathrm{LDH}$ and CEA, and survival rates of colorectal cancers. The proportion of lymphatic invasion was present in $27 \%$ of patients in group A vs. $12 \%$ in group B. With median follow-up of 69 months, the overall 5-year survival rate was $61 \%$ in group A and $56 \%$ in group B. In the univariate survival analysis according to age groups (group A and B), advanced TNM stage, location of rectal tumor, presence of lymphatic invasion, and presence of high serum LDH and CEA levels are predictors of poorer survival in young patients with colorectal cancer. In the Cox-Regression analysis, location of tumor and TNM stage were determined as independent prognostic factors for survival. This study revealed no difference in

Received May 9, 2002; revision accepted for publication February 24, 2003.

Address for reprints: Dr. Süleyman Alıcı, M.D., Yüzüncü Yıl Üniversitesi Tıp Fakültesi, Araştırma

Hastanesi, Tibbi Onkoloji BD, Van 65200, Turkey.

e-mail: suleymanalici@yahoo.com 
clinicopathologic characteristics in patients with colorectal cancer aged 40 years or younger compared with those aged above 40 years. However, in patients aged 40 years or younger, distal location of tumor and advanced stage should be considered as poor prognostic factors for overall survival._— colorectal carcinoma; age factors; prognostic factors

(C) 2003 Tohoku University Medical Press

Although colorectal cancer occurs predominantly in older adults, it does affect young adults with an incidence varying between 1.6\% and 23\% (Sanfelippo and Beahrs 1974; Cusack et al. 1996). The clinicopathologic features and prognosis of colorectal tumors in the young continue to be debated in comparison with those in older patients. Some reports have suggested the unfavourable prognosis of this disease when it occurs in young adults (Isbister 1992; Molnar et al. 1994). This is attributed in most series to the more advanced stage at presentation (Adloff et al. 1986). It is reported that, because of the rarity of this disease in the young, the diagnosis is often delayed (Adloff et al. 1986). Of interest, location of tumor as distal colorectal cancer in the young population may contribute to the poor outcome (Umpleby and Williamson 1984; Nakamura et al. 1999). The aim of this study was to determine the clinicopathologic features at presentation of colorectal cancer and their impact on patients survival in patients aged 40 years or younger, and to compare them with those of older patients.

\section{Patients and Methods}

The records of 466 patients with nonmetastatic colorectal adenocarcinoma who were referred between 1991 and 1999 to the University of Istanbul, Institute of Oncology, following curative surgery were retrospectively analysed. Stage II and III patients who had no macroscopic or microscopic residual disease following surgery, and those who only received chemotherapy for colon tumor or chemotherapy following radiotherapy for rectum tumor as adjuvant treatment were selected for study group.

The age of 41 years was used to separate the patients into two groups: "young" (aged under 41 years; group A) and "old" (41 years and above; group B). Of these patients, 84 (18\%) were younger than 41 years. Group B was subdivided into group K (41-50 years), group L (51-60 years), group M (61-70 years), and group $\mathrm{N}$ ( $\geqq 71$ years). The diagnosis of colon or rectal cancer was initially made during the operation by the surgeon and later confirmed by histopathologic analysis. The clinical data of each of these patients were analysed for age at time of operation, sex, performance status, location of tumor, stage, tumor differentiation, serum levels of lactate dehydrogenase (LDH) (normal range: 240-480 $\mathrm{U} /$ liter) and carcinoembryonic antigen (CEA) (normal range: $0-3.4 \mathrm{ng} / \mathrm{ml}$ ), and lymphatic invasion. The UICC/TNM staging system was used for the staging of lesions after operation with review of the pathological specimen and investigations for distant metastases; T3$4 \mathrm{~N} 0 \mathrm{M} 0$ composed stage II and T1-4N1-3M0 stage III. Histologic grade was recorded as 1 : well differentiated; 2: moderately differentiated; and 3: poorly differentiated. The presence of mucinous histology was also noted. The presence or absence of lymphatic was recorded. All histopathological analyses were performed by one gastrointestinal histopathologist.

All patients were followed up with 3 monthly intervals for the first year, with 6 monthly intervals for the second year and annually thereafter. All surviving patients have had a follow-up period of a minimum of 3 months. Follow-up was available for all patients. Two 
age groups were compared with regard to patients' sex, performance status, disease stage, tumor characteristics, serum levels of $\mathrm{LDH}$ and CEA, and survival. The data of the 84 young patients with colorectal cancer were analysed to determine prognostic factors for survival.

\section{Statistics}

Variables were compared by Chi-square analysis (Brown and Hollander 1977). Overall survival measured from the time of tumor resection until death from any cause, whereas disease-free survival was measured from the time of resection until death or progression of disease. Survival curves were determined by the Kaplan-Meier method and differences in survival were compared by the the log-rank test (Kaplan and Meier 1985; Matthews and Farewell 1988). The potential influence of the other variables on the relationship with age was investigated by adding these to the Cox model already including age (Parmar and Machin 1997). Statistical analysis was performed with the packed program SPSS 7.5.

\section{RESULTS}

\section{Incidence and patients' demography}

Characteristics of patients with respect to age are presented in Table 1 . Patients under the age of 41 years (group A) with colorectal cancer constituted 18 percent of the 466 patients operated on for primary colorectal cancer. There were 36 (43\%) female patients and 48 (57\%) male patients in group A. This sex distribution was similar in group $\mathrm{B}$, which included 188 (49\%) women and 194 (51\%) men. The median age of all patients with colorectal cancer was 55 (range 16-86) years. In young patients, the median age was 35 (range 16-40) years, and among the elderly was 59 (range 41 -86) years.

\section{Clinical characteristics}

There was no statistical difference in tumor sites between group A and group B. The most common sites for cancer occurrence were the rectum and sigmoid colon in both groups of patients. Tumor type of all patients was adenocarcinoma with more aggressive mucinous adenocarcinoma accounting for only 7 and $5 \%$ in groups A and B respectively. Analysis of tumor differentiation in the two groups did not reveal any significant difference. Younger patients had more poorly differentiated tumors (80\%) and mucinous adenocarcinomas $(7 \%)$ than the older group $(p=0.34)$. There was no difference in the TNM stage $(p=$ $0.08)$, T stage $(p=0.71)$ and $\mathrm{N}$ stage $(p=0.08)$ at presentation between groups A and B. TNM stage III tumors were more frequent in younger patients, and stage II tumors were more frequent in older patients. A statistically significant proportion of tumors in group A according to group $\mathrm{B}$ was lymphatic invasion (27\% and $12 \%$, respectively) $(p=0.032)$. There was no statistically significant difference between group $\mathrm{A}$ and $\mathrm{B}$ in the performance status, site of tumor, and serum levels of $\mathrm{LDH}$ and CEA of colorectal cancers.

\section{Survival}

Median follow-up in all patients was 69 (range: 3-108) months. Median follow-up in group $\mathrm{A}$ and $\mathrm{B}$ patients were 84 months and 68 months, respectively $(p=0.76)$. The 5 -year survival rates for patients with TNM stage II and III lesions were 64 and 49 percent, respectively $(p=0.006)$. Patients in group A had a 5-year survivals rate of 61 percent compared with 56 percent in group $\mathrm{B}(p=0.76)$. Tumor recurrence both locally and distant following curative resection was also compared and there was no significant difference between groups $\mathrm{A}$ and $\mathrm{B}$, for the 5-year disease-free survival rate was 69 and 62 percent, respectively. When stratified by age into groups $\mathrm{A}, \mathrm{K}, \mathrm{L}, \mathrm{M}$ and $\mathrm{N}$, the survival curves revealed that the elderly (group $\mathrm{N}$ ) do poorly since the expected years of remaining life are fewer in this group irrespective of disease (Fig. 1). Patients in group $\mathrm{M}$ had a better 
TABLE 1. Characteristics of 466 patients with respect to age

\begin{tabular}{|c|c|c|c|c|c|}
\hline & \multicolumn{2}{|c|}{ Group A } & \multicolumn{2}{|c|}{ Group B } & \multirow{2}{*}{$p$-value } \\
\hline & $n$ & $\%$ & $n$ & $\%$ & \\
\hline All patients & 84 & 18 & 382 & 82 & \\
\hline \multicolumn{6}{|l|}{ Sex } \\
\hline Female & 36 & 43 & 188 & 49 & \\
\hline Male & 48 & 57 & 194 & 51 & 0.921 \\
\hline \multicolumn{6}{|l|}{ ECOG PS ${ }^{1}$} \\
\hline $0-1$ & 45 & 54 & 173 & 45 & \\
\hline $2-4$ & 39 & 46 & 209 & 55 & 0.162 \\
\hline \multicolumn{6}{|l|}{$\mathrm{T}$ stage } \\
\hline $\mathrm{T} 1+\mathrm{T} 2$ & 7 & 8 & 35 & 9 & \\
\hline $\mathrm{T} 3+\mathrm{T} 4$ & 77 & 92 & 347 & 91 & 0.712 \\
\hline \multicolumn{6}{|l|}{$\mathrm{N}$ stage } \\
\hline N0 & 35 & 42 & 200 & 52 & \\
\hline $\mathrm{N} 1+\mathrm{N} 2$ & 49 & 58 & 182 & 48 & 0.082 \\
\hline \multicolumn{6}{|l|}{ TNM stage } \\
\hline $\mathrm{I}+\mathrm{II}$ & 35 & 42 & 200 & 52 & \\
\hline III & 49 & 58 & 182 & 48 & 0.082 \\
\hline \multicolumn{6}{|l|}{ Histologic grade } \\
\hline $\mathrm{I}+\mathrm{II}$ & 9 & 13 & 63 & 19 & \\
\hline $\mathrm{III}+$ Mucinous & 62 & 87 & 279 & 81 & 0.344 \\
\hline Unknown & 13 & & 40 & & \\
\hline \multicolumn{6}{|l|}{ Location of tumors } \\
\hline Colon & 46 & 55 & 208 & 54 & \\
\hline Rectum & 38 & 45 & 174 & 46 & 0.925 \\
\hline \multicolumn{6}{|l|}{$\mathrm{LDH}^{2}$} \\
\hline Normal & 14 & 35 & 64 & 38 & \\
\hline$>$ Normal & 26 & 65 & 106 & 62 & 0.859 \\
\hline Unknown & 44 & & 212 & & \\
\hline \multicolumn{6}{|l|}{$\mathrm{CEA}^{3}$} \\
\hline Normal & 24 & 43 & 152 & 50 & \\
\hline$>$ Normal & 32 & 57 & 151 & 50 & 0.407 \\
\hline Unknown & 28 & & 79 & & \\
\hline \multicolumn{6}{|l|}{ Lymphatic invasion } \\
\hline Absent & 27 & 73 & 154 & 88 & \\
\hline Present & 10 & 27 & 21 & 12 & 0.032 \\
\hline Unknown & 47 & & 207 & & \\
\hline
\end{tabular}

${ }^{1}$ WHO performance status according to the Eastern Cooperative Oncology Group.

${ }^{2}$ lactate dehydrogenase, ${ }^{3}$ carcinoembryonic antigen.

prognosis but a poorer outlook than those in the immediately younger group (group L). The survival curve for group A was closer to that of groups $\mathrm{K}$ and L than that group M (Fig. 1).

The 5-year survival rates for all patients aged less than 71 is $58 \%$, suggesting a trend for higher survival rate than that in group $\mathrm{N}(p=0$. 24) (Table 2). The survival rates for group $A$ is closer to that of groups $\mathrm{K}$ and $\mathrm{L}$ than that of the immediately older patients in group $\mathrm{M}$. 


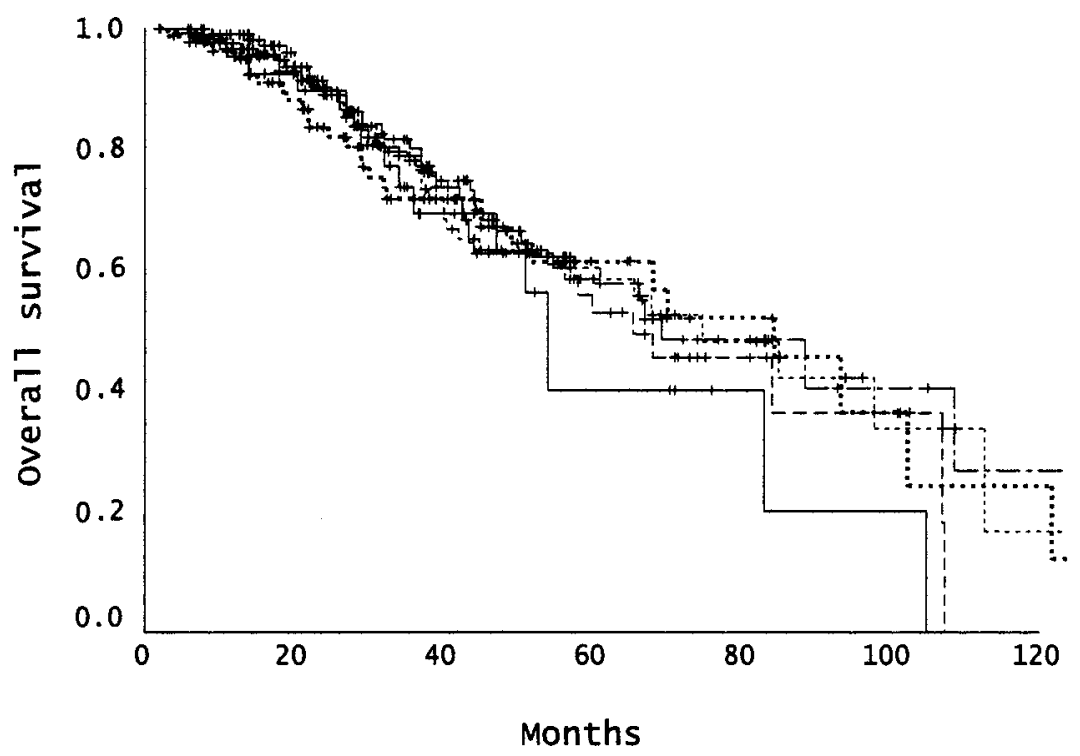

Fig. 1. Overall survival by age groups. (-, N: $\geqq 71$ years; --, M: $61-70$ years; --, L: $51-60$ years; --, K: 41-50 years; ..., A: $<41$ years).

TABLE 2. Univariate survival analysis according to age groups

\begin{tabular}{ccccc}
\hline $\begin{array}{c}\text { Age } \\
\text { (years) }\end{array}$ & Groups & $\begin{array}{c}\text { No. of } \\
\text { patients }\end{array}$ & $\begin{array}{c}\text { 5-years OS } \\
\text { rates }(\%)\end{array}$ & $p$-value \\
\hline$\leqq 40$ & $\mathrm{~A}$ & 84 & 61 & \\
$41-50$ & $\mathrm{~K}$ & 91 & 60 & \\
$51-60$ & $\mathrm{~L}$ & 119 & 58 & \\
$61-70$ & $\mathrm{M}$ & 127 & 53 & 0.78 \\
$\geqq 71$ & $\mathrm{~N}$ & 45 & 40 & \\
\hline \multicolumn{5}{r}{ Overall survival }
\end{tabular}

Univariate survival analysis according to age groups (group A and B) in the patients with colorectal cancer revealed significant survival differences for TNM stage $(p=0.007)$, location of tumor ( $p=0.0001)$, lymphatic invasion $(p=0$. $047)$, serum levels of LDH $(p=0.004)$, and serum levels of CEA $(p=0.0003)$ at presentation (Table 3). TNM stage III, location of rectum tumor, present of lymphatic invasion, and presence of high serum LDH and CEA levels are predictors of poorer survival in young patients with colorectal cancer. Other prognostic variables such as performance status, tumor differentiation, and sex did not have significant impact on survival.
In a multivariate analysis the following pre-treatment factors were included: TNM stage, location of tumor, lymphatic invasion, serum levels of LDH and CEA at presentation. After stepwise exclusion and inclusion, TNM stage (Fig. 2) and location of tumor (Fig. 3) were determined as independent prognostic factors for survival $(p=0.0001)$. Serum levels of LDH showed a tendency towards poorer outcome, but did not reach statistical significance $(p=0.076)$.

\section{DISCUSSION}

Colorectal cancer is seen mostly among patients older than 40 years of age. Although predominantly a disease of older adults, colorectal cancer affects the younger population with an incidence of 1.6 to 23\% (Sanfelippo and Beahrs 1974; Cusack et al. 1996). It is thought to carry a less favourable prognosis in the young than in the general population. An aggressive behaviour is a frequently cited as characteristic of colorectal cancer in young patients (Shahrudin and Noori 1997; de Silva et al. 2000; Mitry et al. 2001). Little is known about colorectal cancer in young patients at a population level, and the behaviour, characteris- 
TABLE 3. Outcome of overall survival according to age in relation to characteristics

\begin{tabular}{|c|c|c|c|c|c|}
\hline & \multicolumn{2}{|c|}{$\leqq 40$ years } & \multicolumn{2}{|c|}{$>40$ years } & \multirow[b]{2}{*}{$p$-value } \\
\hline & $n$ & $\begin{array}{c}\text { 5-years } \mathrm{OS}^{1} \\
\text { rate }(\%)\end{array}$ & $n$ & $\begin{array}{l}5 \text {-years OS } \\
\text { rate }(\%)\end{array}$ & \\
\hline All patients & 84 & 61 & 382 & 56 & 0.764 \\
\hline \multicolumn{6}{|l|}{ Sex } \\
\hline Female & 36 & 65 & 188 & 63 & \\
\hline Male & 48 & 60 & 194 & 48 & 0.325 \\
\hline \multicolumn{6}{|l|}{ ECOG PS ${ }^{2}$} \\
\hline $0-1$ & 45 & 61 & 173 & 62 & \\
\hline $2-4$ & 39 & 60 & 209 & 49 & 0.591 \\
\hline \multicolumn{6}{|l|}{$\mathrm{T}$ stage } \\
\hline $\mathrm{T} 1+\mathrm{T} 2$ & 7 & 63 & 35 & 76 & \\
\hline $\mathrm{T} 3+\mathrm{T} 4$ & 77 & 50 & 347 & 53 & 0.043 \\
\hline \multicolumn{6}{|l|}{$\mathrm{N}$ stage } \\
\hline N0 & 35 & 63 & 200 & 65 & \\
\hline $\mathrm{N} 1+\mathrm{N} 2$ & 49 & 60 & 182 & 46 & 0.007 \\
\hline \multicolumn{6}{|l|}{ TNM stage } \\
\hline $\mathrm{I}+\mathrm{II}$ & 35 & 63 & 200 & 65 & \\
\hline III & 49 & 46 & 182 & 60 & 0.007 \\
\hline \multicolumn{6}{|l|}{ Histologic grade } \\
\hline $\mathrm{I}+\mathrm{II}$ & 9 & 61 & 63 & 53 & \\
\hline III + Mucinous62 & 43 & 279 & 53 & 0.912 & \\
\hline \multicolumn{6}{|l|}{ Location of tumor } \\
\hline Colon & 46 & 81 & 208 & 65 & \\
\hline Rectum & 38 & 39 & 174 & 47 & 0.0001 \\
\hline \multicolumn{6}{|l|}{$\mathrm{LDH}^{3}$} \\
\hline Normal & 14 & 94 & 64 & 70 & \\
\hline$>$ Normal & 26 & 57 & 106 & 35 & 0.0047 \\
\hline \multicolumn{6}{|l|}{$\mathrm{CEA}^{4}$} \\
\hline Normal & 24 & 73 & 152 & 57 & \\
\hline$>$ Normal & 32 & 52 & 151 & 47 & 0.0003 \\
\hline \multicolumn{6}{|l|}{ Lymphatic invasion } \\
\hline Absent & 27 & 70 & 154 & 49 & \\
\hline Present & 10 & 34 & 21 & 28 & 0.047 \\
\hline
\end{tabular}

${ }^{1}$ Overall survival.

${ }^{2} \mathrm{WHO}$ performance status according to the Eastern cooperative Oncology Group.

${ }^{3}$ Lactate dehydrogenase.

${ }^{4}$ Carcinoembryonic antigen.

tics, and prognosis of such tumors continue to be debated. It is believed by some that young patients with cancer have a worse outcome because of an aggressive tumor biology, different tumor distribution, and advanced stage (Bedikian et al. 1981).

While the youngest patients may have a higher rate of survival than expected, the prognosis for patients aged 40 years or younger, 41 $-50,51-60$ and $61-70$ years was not significantly different. These finding are in accordance with those reported in the literature (Chung et al. 1998). It may become more apparent whether young age is a poor prognostic marker as these 


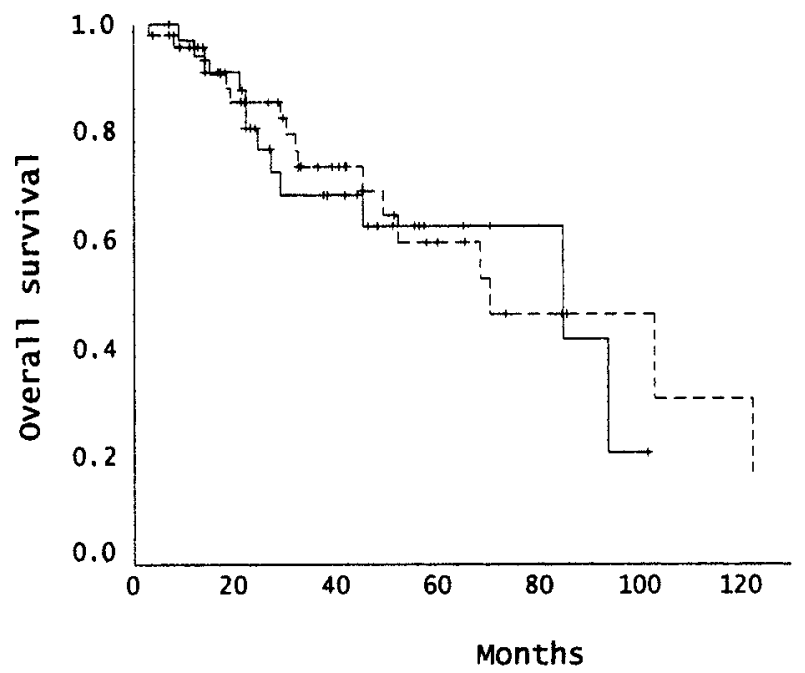

Fig. 2. Overall survival according to TNM stage (--, TNM stage III; -, TNM stage I+II).

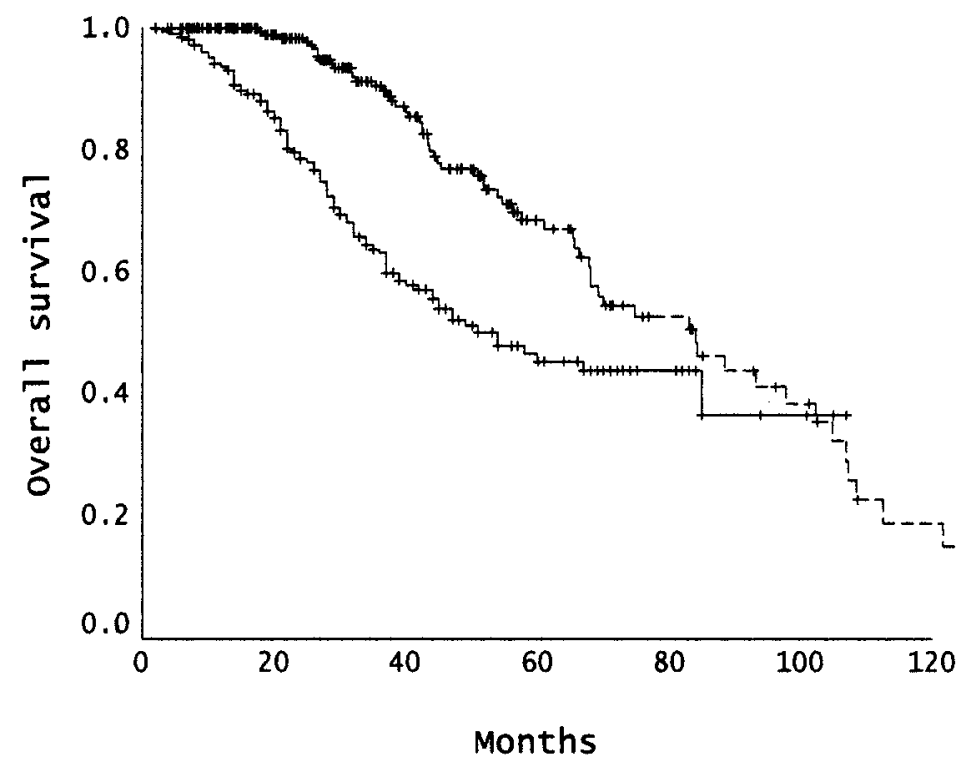

Fig. 3. Overall survival according to location of tumor (--, colon; -, rectum).

patients are followed up for a longer period of time.

Inherent to the discussion is the possible explanation for the unfavourable prognosis of the young patients with colorectal cancer. In larger series reviewed, there is a greater proportion of poor prognostic tumor variables, such as mucinous and poor grade tumors, in the young than in the old (Cusack et al. 1996). Other histopathological indicators of aggressive tumor biology include infiltrating tumor edge, and venous, perineural and lymphatic invasion (Cusack et al. 1996). There was no difference in any of these tumor variables between young and old patients, except for lymphatic invasion in this study.

Stage is one of the most common reproducible independent variables affecting prognosis. In most series, be it the result of aggression of the tumor itself or delay in diagnosis, the young seem to have more advanced stage tumor at presentation than the old (Chung et al. 1998). 
However, the distribution of stage at presentation in this study was similar between the two age categories.

Another important prognostic factor for overall survival in this study was the location of tumor. Our results showed that the overall survival improved as the tumor was more proximal. These finding are in accordance with those reported in the literature (Umpleby and Williamson 1984; Nakamura et al. 1999).

Lymphatic invasion, serum levels of $\mathrm{LDH}$ and CEA have been considered as prognostic factors in other studies (Phillips et al. 1984; Goh and Wong 1992; Lorenz 1993). Although these factors were found to be significant in univariate analysis, this finding was not evident in multivariate analysis in our study.

In the univariate survival analysis according to age groups (group A and B), advanced TNM stage, location of rectum tumor, present of lymphatic invasion, and presence of high serum $\mathrm{LDH}$ and CEA levels are predictors of poorer survival in young patients with colorectal cancer in our study. In the CoxRegression analysis, location of tumor and TNM stage were determined as independent prognostic factors for survival in patients with colorectal cancer aged 40 years or younger compared with those aged above 40 years. In patients aged 40 years or younger, location of distal tumor and advanced stage should be considered as poor prognostic factors for overall survival.

The results of this analysis indicate that patients aged 40 years or younger with colorectal cancer have clinicopathologic characteristics and stage at presentation similar to those of older patients. On a stage-for-stage basis, the survival of these patients is no different from that of older colorectal patients. However, in younger patients showed significant difference in stage and location of tumor-related survival when compared to older populations with the disease.

\section{References}

Adloff, M., Arnaud, J.P., Schloegel, M., Thibaud, D. \& Bergamaschi, R. (1986) Colorectal cancer in patients under 40 years of age. Dis. Colon. Rectum., 29, 322-325.

Bedikian, A.Y., Kantarjian, H., Nelson, R.S., Stroehlein, J.R. \& Bodey, G.P. (1981) Colorectal cancer in young adults. So. Med. J., 74, 920-924.

Brown, B.N. \& Hollander, M. (1977) Statistics: Abiomedical introduction. New York, John Wiley \& Sons., 181-193.

Chung, Y.F., Eu, K.W., Machin, D., Ho, J.M., Nyam, D.C., Leong, A.F., Ho, Y.H. \& Seow-Choen, F. (1998) Young age is not a poor prognostic marker in colorectal cancer. Br. J. Surg., 85(9), 1255-1259.

Cusack, J.C., Giacco, G.G., Cleary, K., Davidson, B.S., Izzo, F., Skibber, J., Yen, J. \& Curley, S.A. (1996) Survival factors in 186 patients younger than 40 years old with colorectal adenocarcinoma. J. Am. Coll. Surg., 183(2), $105-112$.

de Silva, M.V., Fernando, M.S. \& Fernando, D. (2000) Comparison of some clinical and histological features of colorectal carcinoma occurring in patients below and above 40 years. Ceylon. Med. J., 45(4), 166-168.

Goh, H.S. \& Wong, J. (1992) The singapore polyposis registry. Ann. Acad. Med. Singapore, 21, 290-293.

Isbister, W.H. (1992) Colorectal cancer below age 40 in the Kingdom of Saudi Arabia. Aust. N. Z. J. Surg., 62, 468-472.

Kaplan, E.L. \& Meier, P. (1985) Nonparametric estimation from incomplete observations. $J$. Am. Stat. Assoc., 53, 457-481.

Lorenz, M., Hottenrott, C. \& Encke, A. (1993) Adjuvant regional chemotherapy after resection of liver metastases of primary colorectal tumors. Zentralbl. Chir., 118(5), 279-829.

Matthews, D.E. \& Farewell, V.T. (1988) The logrank or Mantel Haenzel test for the comparison of survival curves. (Chapter 7). In: Using and understanding medical statistics. Basel, Skarger, 79-87.

Mitry, E., Benhamiche, A.M., Jouve, J.L., Clinard, F., Finn-Faivre, C. \& Faivre, J. (2001) Colorectal adenocarcinoma in patients under 45 years of age: comparison with older patients in a well-defined French population. Dis. 
Colon. Rectum, 44(3), 380-387.

Molnar, L., Koves, I. \& Besznyak, I. (1994) Malignant colorectal tumors in young adults. Acta. Chir. Hung., 34, 133-138.

Nakamura, T., Yoshioka, H., Ohno, M., Kuniyasu, T. \& Tabuchi, Y. (1999) Clinicopathologic variables affecting survival of distal colorectal cancer patients with macroscopic invasion into the adjacent organs. Surg. Today., 29(3), 226-232.

Parmar, M.K.B. \& Machin, D. (1997) Survival analysis: A pratical approach. Chichester: Wilev.
Phillips, R.K., Hittinger, R., Blesovksy, L., Fry, J.S. \& Fielding, L.P. (1984) Large bowel cancer. Surgical Pathology and its relationship to survival. Br. J. Surg., 71, 604-610.

Sanfelippo, P.M. \& Beahrs, O.H. (1974) Carcinoma of the colon in patients under forty years of age. Surg. Gynecol. Obstet., 138, 169-170.

Shahrudin, M.D. \& Noori, S.M. (1997) Cancer of the colon and rectum in the first three decates of life. Hepatogastroenterology, 44(14), 441-444.

Umpleby, H.C. \& Williamson, R.C.N. (1984) Carcinoma of the large bowel in the first four decades. Br. J. Surg., 71, 272-277. 